\section{European computing}

\section{French bid to build centre}

TOULOUSE in the south of France - a French centre for the aerospace industries, biotechnology and astrophysics - is making a serious play to become a major European focus for research and training in advanced scientific computation. The aim is to bring together computer scientists interested in new architectures (array or parallel processing, multi-instructionstream computers and beyond), users and numerical analysts in a melting-pot that would be unique at least in Europe.

The Toulouse centre as at present planned would at least match a combination of the US National Aeronautics and Space Administration (NASA)'s Langley Institute of Computer Applications in Science and Engineering (ICASE) at Hampton, Virginia and the new NASA Research Institute for Advanced Computer Science (RIACS), which started just a few months ago at Ames, California.

This is not, however, a European "fifth generation"' artificial intelligence (AI) experiment, although the Toulouse association for the promotion of the Centre Européen de Recherche et de Formation Avancé en Calcul Scientifique (CERFACS) wants to have available the most advanced computer possible, and is aiming to have its real impact in the $1990 \mathrm{~s}$.

The CERFACS objective is less ambitious than AI, and possibly more realistic. It stems from a growing feeling among "number crunchers" of all kinds that the new computer architectures and components require radically new techniques, and that interaction between users and computer designers is becoming essential. For example, says Professor Roger Hackney of the Department of Computer Science at the University of Reading, architectures designed to match particular problems can now be "a very cost-effective way of getting large computer power to the problem".

The best use of future and existing machines can be best learned and developed, it is felt, in a centre combining the disciplines of computer science (architectures), numerical analysis (algorithms) and applications specialisms. CERFACS would be such a centre. Nothing like it exists in Europe, Hackney claims. Moreover, NASA's ICASE and RIACS, while addressing all the relevant issues, concentrate architecture on the west coast and applications on the east.

Training and networking would also be "very important" at CERFACS. Visitors would come for several weeks or months, but then return to their home institutions, from which they would wish to keep in touch with CERFACS and use its computing power. So a satellite-based computer communications network is also proposed.

But will CERFACS get off the ground? The idea was the brainchild of Jean-Paul

\section{NIH}

Zahn, director of the Pic du Midi Observatory near Toulouse, but it has now been taken up with enormous enthusiasm by local industry and politicians such as the local mayor and European parliamentarian Henri Sabi.

However, the news from Brussels is not bright. Although the European Commission has set up a "study" of CERFACS, "we learned last week there's little prospect of Brussels cash in the next five years", said a CERFACS spokeswoman in Toulouse last week. "It just takes that long for the Commission to set up a programme."

So the hunt is on for support from the French government (said to be "very positive" to the idea), and from elsewhere. A European support committee has been established with members from the United
Kingdom, West Germany, the Netherlands, Spain, Greece, Denmark and Switzerland, which will report back early next year with the results of its approaches to government and other agencies.

CERFACS does have one guarantee: a purpose-built building. The Midi-Pyrenées regional government will pay for that. Internationally, Greece has already shown great interest, and smaller European nations may well prove more favourable than, say, Britain and West Germany, which already have large machines - even if they do not use them in the CERFACS manner.

France, however, is well behind Britain and West Germany in scientific computing power, so a conceivable outcome is that France will set up a joint arrangement for CERFACS between itself and the smaller nations of Europe. Whatever emerges from present soundings, a formal proposal to the French government will follow, probably in February.

\title{
Academy recommends guile
}

\section{Washington}

A NATIONAL Academy of Sciences panel, after a year-long study, has suggested that the National Institutes of Health (NIH) might best defend themselves against the pressures of the "disease of the month club" by the time-honoured government strategy of injecting a new layer of bureaucracy into the organization. In recent years, a growing number of disease lobbies, acting through Congress, have pressed for the creation of new NIH institutes bearing the name of "their" disease. NIH has resisted these forces with varying success, but recently scored a victory when President Reagan vetoed a bill that would have established new National Institutes of Arthritis and of Nursing.

The academy recommendation is that there should be a new advisory body, to be called the Health Science Board, whose major purpose, it appears, would be to rechannel the public pressures that now find expression through Congress. The board would "communicate public perceptions of health research needs" to NIH and other Public Health Service agencies and would "assure the public that these needs are being . . . addressed".

Proposals for new NIH institutes would be subject to a formal review by the board, which would apply five criteria that would specifically exclude institutes whose major function is regulation, health services or other non-research activities. By these criteria, the National Institute for Occupational Safety and Health and the National Centers for Health Services Research and for Health Statistics - all of which, at some time, have been considered for incorporation into NIH - would be excluded.

The academy panel would not comment on specific proposals, such as that for an arthritis institute, but advised that with NIH now having grown to 11 institutes, there should be a "presumption" against new additions. The panel's survey of NIH's organizational and budget history failed to produce evidence to substantiate the most often-heard justification for new institutes - that they boost support for the particular area of research and thus for $\mathrm{NIH}$ as a whole. (A spokesman for the Arthritis Foundation, for example, told the panel at a public hearing last year that by so visibly responding to such politicallypopular health issues as arthritis, NIH could only gain. "We must see how we can take advantage of the system.")

By contrast, the panel concluded that new institutes add overhead costs, add to the administrative burden of an already overburdened NIH director (25 officials already report directly to him) and hinder scientific communication within NIH.

If the assurances of the Health Science Board are not enough to convince the public that their perceived health research needs are being met, NIH could avail itself of a "continuum" of options short of creating new institutes, the academy panel said. These options include "publicizing what scientific research has accomplished", holding conferences, naming special panels and creating new divisions or programmes within existing institutes.

A somewhat more tangible recommendation of the panel in helping NIH to respond to changing health research needs is for the creation of a contingency fund of 1 per cent of NIH's budget that the director could apply to health emergencies. At current spending, that one per cent equals about $\$ 50$ million, which may be more of a slush fund than Congress would be willing to create.

Stephen Budiansky 